\title{
META ANALISIS MISKONSEPSI BUKU TEKS BIOLOGI SMA KELAS XI
}

\author{
Muthia Hanifah dan Zulyusri \\ Universitas Negeri Padang \\ e-mail: muthia.hanifah98@gmail.com
}

\begin{abstract}
Abstrak
Miskonsepsi adalah perbedaan antara konsep yang dipahami dengan penjelasan para ahli. Penelitian ini bertujuan untuk menganalisis kembali miskonsepsi pada buku teks Biologi SMA kelas XI. Penelitian ini menggunakan metode meta analisis. Meta Analisis merupakan penelitian yang membahas artikel sejenis. Teknik pengumpulan data yaitu dengan mengumpulkan artikel-artikel yang berkaitan dengan miskonsepsi pada buku teks Biologi. Penelitian spesifik dengan miskonsepsi pada buku teks Biologi kelas XI SMA berjumlah 8 artikel dari 23 artikel. Hasil penelitian ditemukan miskonsepsi pada buku teks pelajaran Biologi SMA kelas XI dengan kategori rendah dan sedang. Materi dengan miskonsepsi terbesar adalah sistem imun sebesar $58,8 \%$ (miskonsepsi kategori sedang). Untuk 6 jenis buku teks Biologi, nilai rata-rata miskonsepsi pada unit gambar adalah 6,44\%, sedangkan pada unit teks adalah 3,86\%. Urutan kategori miskonsepsi dari yang terbesar hingga terkecil dalam unit teks adalah misidentifications, oversimplifications, overgeneralizations, undergeneralizations, dan obselete concepts and terms. Sedangkan pada unit gambar urutan kategori miskonsepsi mulai dari yang terbesar sampai yang terkecil yaitu oversimplifications, misidentifications, overgeneralizations, obselete concepts and terms, dan undergeneralizations. Kategori overgeneralizations dan obsolete concepts and terms memiliki nilai yang sama. Sedangkan urutan kategori miskonsepsi pada 12 jenis buku teks dari yang terbesar hingga yang terkecil adalah oversimplifications, misidentifications, overgeneralizations, undereneralizations, dan obsolete concepts and terms
\end{abstract}

Kata kunci-miskonsepsi, buku teks biologi, kelas XI

\section{PENDAHULUAN}

Buku merupakan hal penting dalam dunia pendidikan. Buku dan pendidikan ialah dua komponen yang tidak dapat dipisahkan, karena buku merupakan sesuatu yang berperan penting dalam aspek pendidikan [1]. Buku teks merupakan sumber ajar utama yang digunakan siswa dalam pembelajaran. Menurut [2] buku teks sebagai penunjang bagi siswa dalam mendapatkan informasi terkait materi pelajaran, sehingga buku teks harus memenuhi kriteria dan dapat mencapai tujuannya sebagai sumber informasi yang faktual bagi siswa. Buku teks harus memuat beragam konsep yang mengacu pada kurikulum satuan sekolah. Salah satu bidang studi yang dipenuhi dengan berbagai konsep yaitu Biologi. Biologi merupakan suatu ilmu yang dipenuhi dengan berbagai konsep-konsep ilmu sains yang harus dicermati secara teliti. Menurut [3] Biologi merupakan ilmu yang mengandung konsep-konsep yang saling berkaitan antara suatu konsep dengan konsep yang lainnya.

Konsep adalah gagasan yang menggambarkan makna, ciri-ciri dan kejadian tentang sesuatu. Menurut [4] konsep adalah pendefinisian pada sifat-sifat umum. Konsep dapat berada dalam keadaan umum ke keadaan khusus. Konsep memiliki kategori yang mencakup benda (objects), peristiwa (events), orang (peoples), ide-ide (ideas) dan simbol (symbols). [5] menjelaskan jika konsep awal sudah dipahami dengan benar, maka untuk konsep pelajaran selanjutnya akan mudah dikuasai. Penyebab siswa kesulitan dalam membangun konsep pada dirinya adalah konsep awal yang telah dipelajari tidak dipahami dengan benar. Hal tersebut akan menyebabkan miskonsepsi pada siswa.

Miskonsepsi merupakan perbedaan konsep seseorang dalam suatu bidang studi dengan konsep para ahli. Menurut [6] miskonsepsi adalah berbedanya konsep seseorang yang telah dipahaminya dengan konsep ilmuwan pada suatu bidang ilmu tertentu. [7] menjelaskan bahwa miskonsepsi merupakan ketidaksesuaian konsep yang dipahami dalam bidang ilmu tertentu dengan pengertian ilmiah yang dikemukakan oleh para ahli. Ketidaksesuaian konsep ini dapat terjadi tidak hanya pada tingkat SMA, tetapi juga dapat terjadi pada tingkat pendidikan sekolah dasar bahkan hingga jenjang perguruan tinggi. Selain itu, ketidaksesuaian konsep ini juga dapat terjadi pada guru. Miskonsepsi juga ditemukan pada berbagai bidang ilmu sains sepeti Fisika, Biologi, dan Kimia.

Miskonsepsi dapat terjadi karena berbagai faktor, tidak hanya disebabkan oleh kesalahpahaman konsep oleh penyampaian guru, tetapi ada faktor lain yang yang menjadi penyebab terjadinya miskonsepsi pada siswa. 
Miskonsepsi dialami oleh siswa disebabkan siswa salah dalam memahami konsep yang ada di buku, sehingga ketika menjelaskan suatu konsep tersebut, mereka menggunakan pemahaman yang dibangun atas pemahamannya sendiri yang berbeda dengan konsep sebenarnya. Miskonsepsi dapat disebabkan karena siswa salah dalam memahami konsep awal. [8] menjelaskan miskonsespsi juga dapat terjadi karena keterbatasan siswa dalam menghubungkan konsep awal dengan konsep selanjutnya. Bahkan yang lebih memprihatinkan adalah siswa tidak memperbaiki konsep yang salah yang ada pada dirinya, sehingga miskonsepsi masih melekat pada siswa tersebut.

Buku teks sebagai sumber informasi utama bagi siswa dalam mendukung pembelajarannya harus terbebas dari miskonsepsi. Menurut [7] buku teks merupakan salah satu yang bisa menyebabkan miskonsepsi pada siswa, hal ini karena bahasa yang digunakan tidak mudah dipahami siswa atau penjelasan materi yang tidak benar. Miskonsepsi pada buku teks akan menyebabkan miskonsepsi pada siswa bahkan juga pada guru. Guru diharapkan dapat teliti dalam buku teks yang akan dijadikan sumber bacaan dan penunjang dalam pembelajaran. Kualitas buku teks mempengaruhi pemahaman konsep pada siswa hingga ke jenjang pendidikan berikutnya. Menurut [9] buku teks menjadi komponen utama dalam kurikulum di sekolah, salah satu contohnya buku teks pelajaran Biologi SMA berperan penting dalam pengetahuan sains, sebagian besar siswa menggunakan buku teks sebagai sumber belajar, namun tidak semua buku teks yang telah diterbitkan memenuhi kriteria. [5] menjelaskan bahwa banyak buku teks yang diterbitkan oleh penerbit, namun ditinjau dari kualitas dan jenisnya masih ditemukan buku teks yang tidak sesuai antara konsep dan penerapannya, sehingga menyebabkan miskonsepsi pada siswa.

Miskonsepsi pada buku teks dapat disebabkan karena beberapa komponen, baik dari penulis atau editor saat proses penerbitan buku. Penulis buku teks harus terbebas dari miskonsepsi. Konsep yang benar akan mendukung kualitas buku teks yang diedarkan. Disamping itu, faktor lain yang menyebabkan miskonsepsi yaitu saat proses penerbitan. Penerbitan suatu buku melewati berbagai langkah hingga buku dapat diterbitkan dan diedarkan, miskonsepsi yang terdapat dalam buku teks pelajaran bisa saja terjadi karena adanya kesalahan pengetikan ketika proses percetakan. Menurut [10] miskonsepsi yang ditemukan pada buku tidak bisa disimpulkan terjadi akibat miskonsespsi oleh penulis, karena kesalahan dapat terjadi dalam berbagai faktor, bisa terjadi dalam proses percetakan buku tersebut. Proses agar buku dapat diterbitkan melewati berbagai tahapan, maka kemungkinan lain yang dapat terjadi ketika proses penerbitan buku diedit oleh editor, sedangkan editor belum tentu ahli dalam bidang ilmu tersebut sebagaimana penulis yang bisa saja telah terbebas dari miskonsepsi.

Penelitian analisis miskonsepsi pada buku teks sudah banyak dilakukan. Penelitian [11] mengenai Profil Miskonsepsi Buku Teks pada Konsep Enzim dan Metabolisme Sel Kelas XII SMA di Kabupaten Sidoarjo. Buku yang dianalisis berjumlah 8 buku teks dengan berfokus pada materi Konsep Enzim dan Metabolisme Sel. Persentase miskonsepsi pada buku teks A, B, C, D, E, F, G, dan H berada pada rentang 6,3\% - 33,3\%. Ditemukan dua kategori miskonsepsi pada seluruh buku teks yaitu oversimplifications dan misidentifications dengan persentase $61,9 \%$ dan $38,1 \%$. Buku teks yang paling sedikit teridentifikasi miskonsepsi ialah buku teks D dan G, sedangkan buku teks yang paling banyak teridentifikasi miskonsepsi ialah buku teks F. Banyaknya miskonsepsi pada buku teks yang telah diterbitkan dan digunakan oleh siswa dan guru akan berdampak buruk dalam pembelajaran. Miskonsepsi pada siswa akan terjadi berkelanjutan hingga ke jenjang pendidikan berikutnya. Evaluasi terhadap miskonsepsi harus segera dilakukan agar tidak ada lagi miskonsepsi yang berkelanjutan pada siswa. Disamping itu, miskonsepsi akan menyebabkan siswa sulit dalam menganalisis hubungan antar konsep.

Miskonsepsi pada buku teks akan menyebabkan miskonsepsi pada siswa. [12] menjelaskan bahwa miskonsepsi ini perlu untuk segera ditangani, karena akan mengakibatkan terciptanya rantai kesalahan konsep yang tidak terputus. Salah satu upaya untuk menjaga agar pendidikan di Indonesia ini tidak kalah dengan negara maju lainnya yaitu perlu dibenahi berbagai macam kesalahan dalam penanaman konsep pada siswa. Berdasarkan hal tersebut, review berbagai penelitian tentang miskonsepsi pada buku teks Biologi SMA Kelas XI yang telah dilakukan sebelumnya penting untuk dilakukan.

\section{METODE PENELITIAN}

Jenis penelitian yang digunakan dalam penelitian ini adalah meta analisis. Meta analisis merupakan penelitian yang menganalisis dan merangkum kembali hasil penelitian relevan yang telah diteliti sebelumnya. Penelusuran dengan menggunakan kata kunci "miskonsepsi buku teks biologi" didapatkan 23 artikel yang berkaitan dengan miskonsepsi buku teks biologi yang telah diterbitkan secara nasional, sehingga populasi dalam 
penelitian ini berjumlah 23 artikel. Teknik yang digunakan dalam menentukan sampel adalah teknik Purposive Sampling, yaitu teknik pengambilan sampel dengan tujuan atau kriteria tertentu. Sampel dalam penelitian ini berjumlah 8 artikel yang mengkaji secara spesifik miskonsepsi buku teks Biologi kelas XI. Artikel yang menjadi sumber data dalam penelitian ini memiliki variasi judul dengan materi yang berbeda-beda, namun masih dalam cakupan materi Biologi SMA Kelas XI.

Analisis data dalam penelitian ini terdiri atas tiga langkah, yaitu (1) Analisis deskriptif, yaitu mengakumulasi dan menganalisis data; (2) Analisis isi, yaitu menggunakan suatu metode agar menghasilkan kesimpulan; (3) Analisis kritis, yaitu mengevaluasi data yang sudah diperoleh saat studi literatur, serta menyikapi maksud dari suatu peristiwa secara objektif [13].

\section{HASIL DAN PEMBAHASAN}

Analisis miskonsepsi pada buku teks Biologi SMA Kelas XI telah banyak dilakukan sebelumnya.

Berikut data hasil penelitian miskonsepsi pada buku teks Biologi SMA kelas XI dengan metode meta analisis:

Tabel 1. Jumlah Miskonsepsi berbagai materi Biologi SMA Kelas XI

\begin{tabular}{|c|c|c|c|c|}
\hline No & Materi & $\begin{array}{c}\text { Jumlah } \\
\text { Miskonsepsi }\end{array}$ & $\begin{array}{c}\text { Buku yang } \\
\text { analisis }\end{array}$ & Sumber \\
\hline 1. & Sel & 7 & \multirow{5}{*}{$\begin{array}{c}\text { Buku X } \\
\text { Karangan X }\end{array}$} & \multirow{5}{*}[14]{} \\
\hline 2. & $\begin{array}{l}\text { Struktur dan fungsi } \\
\text { jaringan tumbuhan }\end{array}$ & 13 & & \\
\hline 3. & $\begin{array}{l}\text { Struktur dan fungsi } \\
\text { jaringan hewan }\end{array}$ & 18 & & \\
\hline 4. & Sistem gerak & 22 & & \\
\hline 5. & Sistem sirkulasi & 20 & & \\
\hline 6. & $\begin{array}{l}\text { Struktur tumbuhan dan } \\
\text { hewan }\end{array}$ & 1 & \multirow[t]{2}{*}{$\begin{array}{l}\text { Karangan P } \\
\text { Penerbit E }\end{array}$} & \multirow[t]{2}{*}[5]{} \\
\hline 7. & Sistem sirkulasi & 1 & & \\
\hline & Total & 82 & & \\
\hline
\end{tabular}

Pada Tabel 1. menunjukkan miskonsepsi pada 2 jenis buku teks Biologi Kelas XI. Buku teks X merupakan buku teks yang digunakan secara mayoritas oleh siswa di Banda Aceh. Hasil analisis miskonsepsi pada buku teks $\mathrm{X}$ ialah ditemukan miskonsepsi pada setiap materi. Miskonsepsi materi tertinggi yaitu materi sistem gerak dengan jumlah miskonsepsi 22 konsep. Miskonsepsi terendah terdapat pada materi sel dengan jumlah miskonsepsi 7 konsep.

Hasil analisis miskonsepsi pada buku teks penerbit E karangan P tahun 2006 ialah ditemukan miskonsepsi berjumlah 2 konsep yang mengalami miskonsepsi secara utuh, namun konsep lainnya masih ada yang tidak dijelaskan dengan baik, sehingga guru harus menjelaskan dengan lebih detail untuk mencegah terjadinya miskonsepsi pada siswa. Peran guru dalam meluruskan konsep pada siswa sangat dibutuhkan. Total miskonsepsi pada 2 jenis buku teks Biologi yaitu berjumlah 82 konsep. Artinya, nilai kualitas buku teks sudah berkurang disebabkan ditemukannya miskonsepsi pada kedua jenis buku teks, terutama buku Penerbit $\mathrm{X}$ karangan X. Apabila dibandingkan antara 2 jenis buku teks tersebut, maka buku teks Karangan P penerbit E lebih baik kualiatasnya daripada buku teks X Karangan X dalam hal penjelasan konsep, namun kedua buku teks harus dievaluasi lebih lanjut agar terbebas dari miskonsepsi. Miskonsepsi pada buku teks akan menyebabkan miskonsepsi pada siswa bahkan guru. [15] menjelaskan bahwa miskonsepsi dapat terjadi karena buku yang digunakan dalam pembelajaran menjelaskan materi yang berbeda dengan pengertian saintifik ilmuwan.

Tabel 2. Miskonsepsi pada Buku Teks Biologi SMA Kelas XI Materi Sistem Saraf

\begin{tabular}{lcccccccc}
\hline \multicolumn{1}{c}{ Sub materi } & I & II & III & IV & V & VI & VII & Jumlah \\
\hline Struktur dan fungsi neuron & 3 & 1 & 1 & 3 & - & 1 & - & 9 \\
\hline Impuls saraf & 2 & - & - & - & - & 3 & - & 5 \\
\hline Sistem saraf pusat & 3 & 7 & - & 2 & 3 & 1 & 2 & 18 \\
\hline Sistem saraf tepi & 2 & - & - & - & - & 1 & - & 3 \\
\hline Gerak sadar dan refleks & - & - & - & - & - & - & - & 0 \\
\hline
\end{tabular}


Jurnal Biologi dan Pembelajarannya, Vol 8 No 1, April 2021. Pp: 32-39

e-ISSN: $2406-8659$

\begin{tabular}{lcccccccc}
\hline Kelainan sistem saraf & - & - & - & - & - & - & - & 0 \\
\hline Total & 10 & 8 & 1 & 5 & 3 & 6 & 2 & 35 \\
\hline
\end{tabular}

Sumber: [16]

Analisis miskonsepsi pada buku teks dilakukan pada 7 jenis buku. Buku teks diberi kode I - VII. Analisis miskonsepsi dibatasi hanya pada materi sistem saraf (sistem koordinasi) pada 7 buku teks. Hasil penelitian menunjukkan setiap buku teks teridentifikasi adanya miskonsepsi. Miskonsepsi paling banyak ditemukan pada buku teks I dan II, sedangkan miskonsepsi paling sedikit ditemukan pada buku teks III (Tabel 2).

Sub materi sistem saraf yang tidak mengandung miskonsepsi pada 7 jenis buku teks adalah sub materi gerak sadar dan refleks dan kelainan sistem saraf, sedangkan sub materi yang paling banyak mengandung miskonsepsi adalah sistem saraf pusat, sehingga sub materi yang mengalami miskonsepsi pada 7 jenis buku teks yaitu struktur dan fungsi neuron, impuls saraf, sistem saraf pusat, sistem saraf tepi. Total konsep yang mengalami miskonsepsi pada 7 buku teks materi sistem saraf berjumlah 35 konsep, dengan jumlah miskonsepsi paling sedikit ditemukan pada buku teks III berjumlah 1 konsep yang mengalami miskonsepsi. Artinya, buku teks III merupakan buku teks yang paling baik kualitasnya dalam menjelaskan konsep materi sistem saraf dibandingkan 6 buku teks lainnya, berdasarkan hal tersebut guru diharapkan dapat cermat dalam memilih buku teks yang telah diterbitkan. Menurut [17] guru dan peserta didik harus dapat memilih dengan teliti jenis buku teks yang digunakan dalam proses pembelajaran.

Tabel 3. Persentase Kebenaran Konsep dan Miskonsepsi Materi Biologi pada 12 Jenis Buku Teks Biologi Kelas XI

\begin{tabular}{ccccc}
\hline No & $\begin{array}{c}\text { Buku } \\
\text { teks }\end{array}$ & $\begin{array}{c}\text { Persentase } \\
\text { kebenaran konsep }(\%)\end{array}$ & $\begin{array}{c}\text { Persentase } \\
\text { Miskonsepsi } \\
(\%)\end{array}$ & Materi \\
\hline 1. & $\mathrm{~A}$ & 92,8 & 6,2 & Sistem \\
pernapasan & Sumber & Sistem \\
perncernaan \\
manusia
\end{tabular}

Berdasarkan Tabel 3. diketahui bahwa setiap materi pada buku teks yang dianalisis teridentifikasi adanya miskonsepsi. Miskonsepsi yang ditemukan pada buku teks berada pada rentang 5\%-58,8 \%. Menurut [22] miskonsepsi dikategorikan rendah jika presentase miskonsepsi 0 - 30\%, kategori sedang jika presentase miskonsepsi 31\% - 60\% dan kategori tinggi jika presentase miskonsepsi $61 \%$ - 100\%, sehingga dari 12 buku teks Biologi yang dianalisis, 11 buku teks teridentifikasi miskonsepsi dengan kategori rendah, karena presentase miskonsepsi berada pada rentang $0 \%-30 \%$. Buku teks yang tergolong miskonsepsi sedang yaitu buku teks $\mathrm{A}$ materi sistem imun dengan presentase miskonsepsi sebesar 58,8\%. Artinya, mayoritas materi pada beberapa jenis buku teks Biologi kelas XI masih layak dijadikan bahan bacaan bagi siswa, namun evaluasi lebih lanjut terhadap buku teks penting untuk dilakukan agar buku teks terbebas dari miskonsepsi. [23] menjelaskan dalam memberantas miskonsepsi pada buku teks partisipasi antara tim ahli, pengarang, guru dan penerbit sangat dibutuhkan.

Tabel 4. Kategori Miskonsepsi Materi Biologi pada 9 Jenis Buku Teks Biologi Kelas XI

\begin{tabular}{ccccccccc}
\hline \multirow{2}{*}{ No } & Buku & \multicolumn{5}{c}{ Kategori Miskonsepsi } & \multirow{2}{*}{ Materi } & \multirow{2}{*}{ Sumber } \\
\cline { 2 - 6 } & teks & $M I$ & $O G$ & $O S$ & $U G$ & $O C T$ & & Sistem \\
\hline 1. & A & 1 & 2,1 & 3,1 & 0 & 0 & {$[18]$} \\
\hline
\end{tabular}


Jurnal Biologi dan Pembelajarannya, Vol 8 No 1, April 2021. Pp: 32-39

e-ISSN: $2406-8659$

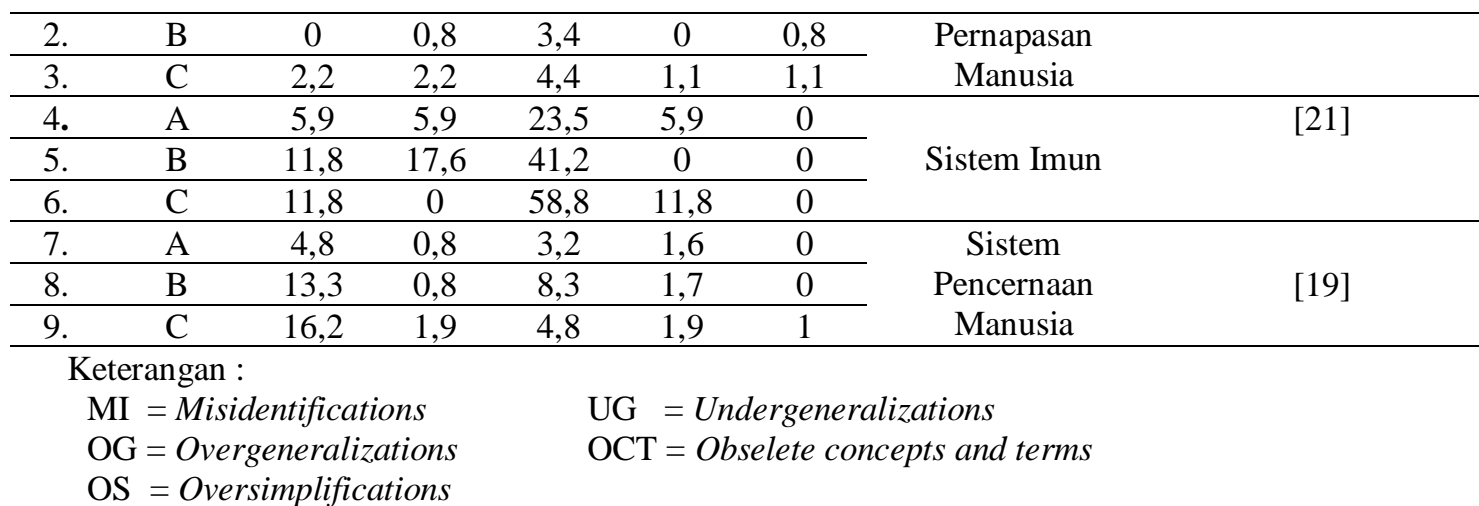

Tabel 4. menunjukkan analisis miskonsepsi buku teks menggunakan kategori miskonsepsi oleh Hersey. Menurut [24] analisis miskonsepsi pada buku teks terdiri atas 5 kategori, yaitu misidentifications (kesalahan identifikasi), undergeneralizations (kurang umum/terlalu khusus), oversimplifications (terlalu sederhana), overgeneralizations (terlalu umum) dan obsolete concepts and terms (konsep dan istilah yang sudah usang). Oversimplifications merupakan kategori miskonsepsi yang ditemukan pada setiap buku teks yang dianalisis. Oversimplifications ditemukan dalam jumlah yang paling tinggi dibandingkan kategori miskonsepsi lainnya. Indikator ditemukannya miskonsepsi pada buku teks dengan kategori oversimplifications ialah konsep yang dikemukakan terlalu sederhana, sehingga konsep menjadi kurang lengkap atau bahkan salah. Penyederhanaan suatu konsep seharusnya tetap sesuai dengan literatur, tidak dikurangi atau bahkan akan mengakibatkan salah konsep. Obsolete concepts and terms merupakan kategori miskonsepsi yang ditemukan hanya pada 2 jenis buku teks, sehingga kategori obsolete concepts and terms merupakan kategori miskonsepsi minimal pada buku teks. Urutan kategori miskonsepsi dari yang terbesar hingga terkecil ditemukan pada beberapa buku teks Biologi SMA Kelas XI yaitu oversimplifications, misidentifications, overgeneralizations, undergeneralizations dan obsolete concepts and terms. Artinya, tidak satupun materi analisis pada buku teks bebas dari miskonsepsi. [15] menjelaskan bahwa salah satu indikator kualitas buku teks ialah konsep yang dijelaskan sesuai dengan pandangan para ahli. Ditemukannya miskonsepsi materi pada buku teks Biologi Kelas XI akan mengurangi mutu buku teks tersebut.

Tabel 5. Miskonsepsi Unit Teks dan Gambar Materi Biologi pada 6 Jenis Buku teks Biologi Kelas XI

\begin{tabular}{|c|c|c|c|c|c|c|c|c|}
\hline \multirow[t]{2}{*}{ No } & \multirow{2}{*}{$\begin{array}{c}\text { Unit } \\
\text { analisis }\end{array}$} & \multicolumn{5}{|c|}{ Kategori miskonsepsi (\%) } & \multirow{2}{*}{ Materi } & \multirow{2}{*}{ Sumber } \\
\hline & & MI & OG & OS & UG & OCT & & \\
\hline \multirow[t]{2}{*}{1.} & Teks & 7,24 & 1,55 & 3,36 & 0,78 & 0,26 & \multirow{2}{*}{ Sistem saraf } & [19] \\
\hline & Gambar & 11,11 & 0 & 17,78 & 0 & 0 & & \\
\hline \multirow{2}{*}{2.} & Teks & 7,86 & 3,68 & 21,87 & 0,25 & 0 & \multirow{2}{*}{$\begin{array}{c}\text { Jaringan } \\
\text { hewan }\end{array}$} & \multirow[t]{2}{*}{ [22] } \\
\hline & Gambar & 37,84 & 0 & 67,57 & 0 & 0 & & \\
\hline \multirow{2}{*}{3.} & Teks & 1,1 & 1,8 & 3,5 & 0,37 & 0,67 & \multirow{2}{*}{$\begin{array}{c}\text { Sistem } \\
\text { pernapasan }\end{array}$} & \multirow[t]{2}{*}{ [17] } \\
\hline & Gambar & 0 & 0 & 12,2 & 0 & 0 & & \\
\hline \multirow{2}{*}{4.} & Teks & 4,3 & 0,9 & 3,5 & 1,7 & 0 & \multirow{6}{*}{$\begin{array}{c}\text { Sistem } \\
\text { pencernaan } \\
\text { manusia }\end{array}$} & \multirow{6}{*}{ [18] } \\
\hline & Gambar & 11,1 & 0 & 0 & 0 & 0 & & \\
\hline \multirow{2}{*}{5.} & Teks & 14,3 & 0,9 & 8,0 & 1,8 & 0 & & \\
\hline & Gambar & 0 & 0 & 12,5 & 0 & 0 & & \\
\hline \multirow{2}{*}{6.} & Teks & 17,4 & 1,1 & 5,4 & 2,2 & 0 & & \\
\hline & Gambar & 7,7 & 7,7 & 0 & 0 & 7,7 & & \\
\hline
\end{tabular}

Keterangan :

$$
\begin{aligned}
& \mathrm{MI}=\text { Misidentifications } \quad \mathrm{UG}=\text { Undergeneralizations } \\
& \mathrm{OG}=\text { Overgeneralizations } \mathrm{OCT}=\text { Obselete concepts and terms } \\
& \mathrm{OS}=\text { Oversimplifications }
\end{aligned}
$$

Berdasarkan Tabel 5. analisis miskonsepsi dilakukan pada 6 jenis buku teks dengan materi analisis pada buku teks Biologi SMA Kelas XI pada analisis unit teks dan gambar tepatnya pada materi sistem saraf 
manusia, jaringan hewan, sistem pernapasan manusia dan sistem pencernaan manusia. Hasil analisis miskonsepsi pada unit teks ditemukan 4 kategori miskonsepsi yaitu misidentifications, overgeneralizations, oversimplifications, undergeneralizations untuk semua jenis buku teks, sedangkan obsolete concepts and terms hanya ditemukan pada 2 jenis buku teks yaitu pada materi sistem saraf dan sistem pernapasan manusia. Adapun miskonsepsi pada unit gambar hanya ditemukan kategori misidentifications, overgeneralizations dan oversimplifications pada semua buku teks yang dianalisis.

Presentase miskonsepsi pada unit gambar lebih besar daripada unit teks. Rata-rata miskonsepsi pada unit gambar sebesar 6,44 \% sedangkan pada unit teks sebesar 3,86\%. Pada unit teks, urutan kategori miskonsepsi dari yang terbesar hingga terkecil pada 6 jenis buku teks Biologi SMA Kelas XI yaitu misidentifications, oversimplifications, overgeneralizations, undergeneralizations dan obsolete concepts and terms. Sedangkan pada unit gambar urutan kategori miskonsepsi dari yang terbesar hingga terkecil yaitu oversimplifications, misidentifications, overgeneralizations, obsolete concepts and terms, undergeneralizations. Untuk kategori overgeneralizations dan obsolete concepts and terms memiliki nilai rata-rata miskonsepsi yang sama. Artinya, mayoritas buku teks yang telah dianalisis sebelumnya memuat kualitas gambar yang masih belum sempurna, dibuktikan dengan ditemukannya miskonsepsi unit gambar pada setiap buku teks yang dianalisis, bahkan rata-rata miskonsepsi unit gambar lebih besar daripada unit teks. Besarnya persentase miskonsepsi pada unit gambar seharusnya menjadi perhatian bagi penulis dan penerbit buku teks, karena siswa cenderung menguatkan konsep dengan gambar yang dimuat buku teks. [23] menjelaskan bahwa besarnya miskonsepsi pada unit gambar akan berpeluang besar menyebabkan miskonsepsi pada siswa, karena siswa memperkuat konsep yang dimilikinya dengan memahami gambar yang dimuat pada buku teks, sehingga jika konsep yang dimiliki siswa sudah benar, namun adanya miskonsepsi gambar pada buku teks miskonsepsi akan melunturkan konsep yang sudah benar pada diri siswa. Miskonsepsi pada unit teks pun juga harus diteliti lebih lanjut agar buku teks sebagai sumber informasi yang dekat dengan siswa terbebas dari miskonsepsi.

\section{SIMPULAN}

1) Berbagai jenis buku teks Biologi SMA kelas XI yang telah dianalisis miskonsepsi pada penelitian sebelumya tidak terlepas dari adanya miskonsepsi.

2) Ditemukan miskonsepsi materi Biologi pada 12 jenis buku teks Biologi SMA kelas XI dengan kategori rendah dan sedang.

3) Urutan kategori miskonsepsi dari yang terbesar hingga terkecil ditemukan pada 12 jenis buku teks Biologi SMA Kelas XI yaitu oversimplifications, misidentifications, overgeneralizations, undergeneralizations dan obsolete concepts and terms.

4) Materi yang mengalami miskonsepsi paling besar yaitu materi sistem imun dengan kategori miskonsepsi sedang.

5) Pada 6 jenis buku teks, presentase miskonsepsi unit gambar lebih besar daripada unit teks. Rata-rata miskonsepsi pada unit gambar sebesar 6,44 \% sedangkan pada unit teks sebesar 3,86 \%.

6) Urutan kategori miskonsepsi dari yang terbesar hingga terkecil pada 6 jenis buku teks Biologi SMA Kelas XI yaitu misidentifications, oversimplifications, overgeneralizations, undergeneralizations dan obsolete concepts and terms, sedangkan pada unit gambar urutan kategori miskonsepsi dari yang terbesar hingga terkecil yaitu oversimplifications, misidentifications, overgeneralizations, obsolete concepts and terms, undergeneralizations. Untuk kategori overgeneralizations dan obsolete concepts and terms memliki nilai yang sama.

\section{SARAN}

1) Miskonsepsi pada buku teks akan berakibat miskonsepsi pada siswa, maka analisis miskonsepsi pada siswa hendaknya diteliti lebih lanjut.

2) Analisis miskonsepsi materi Biologi pada kelas XI yang belum dianalisis hendaknya diteliti lebih lanjut.

\section{UCAPAN TERIMA KASIH}

Terima kasih kepada peneliti terdahulu dan tim ahli yang telah menganalisis miskonsepsi pada beberapa jenis buku teks Biologi SMA Kelas XI. 
Jurnal Biologi dan Pembelajarannya, Vol 8 No 1, April 2021. Pp: 32-39

e-ISSN: $2406-8659$

\section{DAFTAR PUSTAKA}

[1] Jatmika, H. M. 2014. Analisis Kelayakan Isi Buku Teks Penjasorkes Kelas X SMA di Kabupaten Bantul Daerah Istemwa Yogyakarta. Jurnal Pendidikan Jasmani Indonesia, 10(2), 62-67.

[2] Sihombing, R. I., Daulae, A. H., Sari, D. K., dan Sihombing, H. 2017. Analisis Miskonsepsi Buku Teks Biologi SMA Kelas X Materi Eubacteria di Kota Kisaran. Jurnal Pelita Pendidikan, 5(2), 44-48.

[3] Kose, S. 2008. Diagnosing Student Misconceptions: Using Drawing As A Research Method. World Applied Science Journal, 3(2), 283-293.

[4] Lufri. 2007. Strategi Pembelajaran Biologi. Padang: Universitas Negeri Padang Press.

[5] Imran, R.F., Zulyusri \& Advinda, L. 2015. Miskonsepsi pada Buku Teks Biologi SMA Kelas XI Semester I. Jurnal PENDIPA, 2(2), 57-64.

[6] Suparno. P. 2013. Miskonsepsi dan Perubahan Konsep dalam Pendidikan Fisika. Jakarta: PT. Grasindo.

[7] Suparno. P. 2005. Miskonsepsi dan Perubahan Konsep Dalam Pendidikan Fisika. Jakarta: PT. Grasindo Anggota Ikapi.

[8] Farihah, A. N., Pukan, K. K., \& Marianti, A. 2016. Analisis Miskonsepsi Materi Sistem Regulasi Pada Siswa Kelas XI SMA Kota Semarang. Journal of Biology Education, 5(3), 319-329.

[9] Chiappetta, L. E., \& Fillman, A. D. 2007. Analysis of Five High School Biology Textbooks Used in the United States for I nclusion of the Nature of Science. International Journal of Science Education, 29(15), 1847-1868.

[10] Respatiningrum, N., Radiyono Y., dan Wiyono E. 2015. Analisis Miskonsepsi Materi Fluida pada Buku Ajar Fisika SMA. Jurnal Prosiding Seminar Nasional Fisika dan Pendidikan Fisika, 6(1), 313-317.

[11] Putri, B.O.K. 2018. Profil Miskonsepsi Buku Teks pada Konsep Enzim dan Metabolisme Sel Kelas XII SMA di Kabupaten Sidoarjo. Bioedu: Berkala Ilmiah Pendidikan Biologi, 7(3), 468-477.

[12] Kurniasih, M. D. 2017. Analisis Miskonsepsi Mahasiswa dengan Menggunakan Certainty of Response Index (CRI) Pada Materi Anatomi Tubuh Manusia. EduSains: Jurnal Pendidikan Sains \& Matematika, $5(1), 1-11$.

[13] Irani, N.F., Zulyusri, Darussyamsu, R., 2020, Miskonsepsi Materi Biologi SMA dan Hubungannya dengan Pemahaman Siswa. Jurnal Biolokus, 3(2), 348-355.

[14] Fajriana N., Abdullah dan Safrida. 2016. Analisis Miskonsepsi Buku Teks Pelajaran Biologi Kelas XI Semester 1 SMAN di Kota Banda Aceh. Jurnal Biotik, 4(1), 60-65.

[15] Agustina, R., Sipahutar, H, Harahap F. 2016. Analisis Miskonsepsi pada Buku Ajar Biologi SMA Kelas XII. Jurnal Pendidikan Biologi, 5(2), 113-118.

[16] Hidayati, I., Abdullah, Sabri M. 2015. Identifikasi Miskonsepsi Sistem Saraf pada Buku Teks Biologi Kelas XI. Jurnal Biotik, 3(1), 39-44.

[17] Suranti, T., Suratsih, \& Henuhili, V. 2017. Miskonsepsi Materi Genetika dalam Buku Biologi SMA Kelas XII yang ditulis Berdasarkan Kurikulum 2013 di Kabupaten Kulon Progo. Jurnal Prodi Pendidikan Biologi, 6(2), 47-64.

[18] Chairunnisa, S., Sukiya, \& Rahayu, T. 2018. Analisis Miskonsepsi Sistem Pernapasan pada Buku Teks Biologi SMA Kelas XI di Kabupaten Banyumas. Jurnal Prodi Pendidikan Biologi, 7(4), 294-300.

[19] Nugroho, F.A. 2016. Identifikasi Miskonsepsi Sistem Pencernaan Manusia pada Buku Teks Biologi SMA Kurikulum 2013 di Kota Yogyakarta. Jurnal Pendidikan Biologi, 5(5), 13-22.

[20] Ramadhan A.N. 2016. Identifikasi Miskonsepsi Sistem Saraf Manusia dalam Buku Teks Biologi SMA di Kota Yogyakarta. Jurnal Pendidikan Biologi, 5(6), 37-45.

[21] Pangestika, A. \& Widyaningrum T. 2018. Identifying Conceptual Mistakes on SMA Teaching Books in Materials of Imune System for Eleventh Graders. International Journal of Active Learning, 3(2), 50-57.

[22] Suwarna, I.W. 2020. Analisis Miskonsepsi Siswa Kelas X pada Materi Pelajaran Fisika Melalui CRI (Certainty of Response Index) Termodifikasi. UIN Syarif Hidayatullah.

[23] Wijiningsih, T.A., Harjana T., Sukiya. 2016. Analisis Miskonsepsi Materi Struktur-Fungsi Jaringan Hewan dalam Buku Biologi SMA Kelas XI. Jurnal Pendidikan Biologi, 5(7), 70-79.

[24] Hershey, D.R. 2005. More Misconceptions to Avoid When Teaching about Plants. 